\title{
The Appraisal of the thermal properties, electrical response, and corrosion resistance performance of AA8011 reinforced Nano $\mathrm{Si}_{3} \mathrm{~N}_{4}$ for automobile application
}

\author{
J. Fayomi a, b, c, *, A.P.I. Popoola a, b, O.M. Popoola ${ }^{\text {c }}$, O.S.I. Fayomi ${ }^{\text {a, b, d }}$ \\ ${ }^{a}$ Department of Chemical, Metallurgical and Materials Engineering, Tshwane University of Technology, P.M.B. X680, Pretoria, South Africa \\ ${ }^{\mathrm{b}}$ Surface Engineering and Research Laboratory, Tshwane University of Technology, P.M.B. X680, Pretoria, South Africa \\ ${ }^{c}$ Centre for Energy and Electric Power, Department of Electrical Engineering, Tshwane University of Technology, P.M.B. X680, Pretoria, South Africa \\ ${ }^{\mathrm{d}}$ Covenant University, P.M.B. 123, Ota, Nigeria
}

\section{A R T I C L E I N F O}

\section{Article history:}

Received 20 July 2020

Received in revised form

9 August 2020

Accepted 10 August 2020

Available online 20 August 2020

\section{Keywords:}

Stir casting

AA8011/ $/ \mathrm{Si}_{3} \mathrm{~N}_{4}$

Metal matrix composites

Thermal

Corrosion: electrical

\begin{abstract}
A B S T R A C T
AA8011-5 wt $\% \mathrm{Si}_{3} \mathrm{~N}_{4}, \mathrm{AA8011-10} \mathrm{wt} \% \mathrm{Si}_{3} \mathrm{~N}_{4}, \mathrm{AA8011-15} \mathrm{wt} \% \mathrm{Si}_{3} \mathrm{~N}_{4}$, and AA8011-20 wt\% $\mathrm{Si}_{3} \mathrm{~N}_{4}$ were developed via two-steps stir casting route of liquid metallurgy. The influence of the inclusion of the nonconductive inorganic nano ceramic $\mathrm{Si}_{3} \mathrm{~N}_{4}$ on the thermal properties, electrical behavior, and corrosion resistance performance of the conductive AA8011 matrix was investigated. The thermal responses via thermogravimetric analysis (TGA) and differential thermal analysis (DTA) revealed a decrease in the material mass loss and an increase in the melting point temperature with respect to the increase in $\mathrm{Si}_{3} \mathrm{~N}_{4}$ addition respectively as a function of temperature rise in a controlled inert environment. However, the electrical conductivity of the matrix AA8011 decreases with the percentage rise in the weight fraction of $\mathrm{Si}_{3} \mathrm{~N}_{4}$ and resulted in high electrical resistivity of the composite developed. Also, the corrosion behavior of the developed composite was investigated by the potentiodynamic electrochemical process and gravimetric weight loss measurement to evaluate the corrosion rate and the resistance capacity in the simulated seawater environment. The corrosion rate was observed to decrease with $\mathrm{Si}_{3} \mathrm{~N}_{4}$ inclusion, and the composite developed to inhibit or resist corrosion attack by blocking the site of corrosion initiation compared to the unreinforced AA8011. In all, the percentage of performance increases in relation to the efficiency of the nano $\mathrm{Si}_{3} \mathrm{~N}_{4}$.
\end{abstract}

(c) 2020 Elsevier B.V. All rights reserved.

\section{Introduction}

Aluminium alloys generally exhibited exceptional mechanical, electrical conductivity, and corrosion properties that position them as a leading material in current dispensation for most industrial applications, especially in automobile industries. However, it displays poor resistance to wear, corrosion, and low thermal stability mostly in high-temperature applications [1-3]. According to Ref. [4] Azadi et al., 2018, aluminium alloys have been greatly employed in engine pistons of automobile components where the piston materials are subjected to thermal stress. Nevertheless, it is pertinent to improve the thermal properties to withstand the

\footnotetext{
* Corresponding author. Department of Chemical, Metallurgical and Materials Engineering, Tshwane University of Technology, P.M.B. X680, Pretoria, South Africa. E-mail addresses: fayomi_chris@yahoo.com, 218749836@tut4life.ac.za (J. Fayomi).
}

thermal stress and this can be done by reinforcing the aluminium alloy with a second phase. Likewise [5], Kim et al., 2012 acknowledged that the demand for aluminium alloys in the engineering applications that require excellent thermal conductivity is increasing daily. Unfortunately, most of the aluminium die casting alloys possess low thermal stability at high temperatures due to the content of their alloying element. Also, alloys of aluminum (Al) have been established to experience serious corrosion attack mostly in high solution temperature and presence of halide ion. The chloride of halide ion easily gets adsorbed on the aluminium surface thereby breakdown the passive protective film of Al especially at high concentration. So, exposing aluminium to highly prone chloride $\left(\mathrm{Cl}^{-}\right)$environment (aerated or saltwater) often resulted to corrosion threat and degradation of components like auto-parts [6].

Hence, the reinforcement of ductile aluminium alloy with ceramic particles, short fibres, and industrial waste resulted in metal matrix composites with improved wear resistance 
properties, good mechanical behavior, excellent corrosion resistance, and improved thermal stability [7-10].

Fabrication of radiators, pistons, brakes, engine blocks and other automobile components using aluminium metal matrix composite are some of the emerging applications in the automobile industry. Several pieces of research have shown that the corrosion rate decreases, the melting temperature improve, and the electrical resistivity increases with the inclusion of hard reinforcement material [11-14]. However, the inherent properties of the primary aluminium alloy cannot be overridden as it gives the necessary complement of ductility to the reinforcing phase [15].

The major motives for employing and adopting new materials in the automotive industry is to reduce weight, increase fuel economy, reduce the cost of maintenance, and mitigate vehicle emission. Generally, the widespread implementation of the reinforced metal matrix composite (MMC) as a new innovative technology in automobile device attained antecedence only within the last few decades because of its pattern of design, fabrication process, recyclable potential, and improved finish product compared to the monolithic material.

Commercially, the auto industries have been able to develop some components such as piston, engine blocks, caliper, and other parts using $\mathrm{Al} / \mathrm{SiC}$ and $\mathrm{Al} / \mathrm{Al}_{2} \mathrm{O}_{3}$, which are aluminium based composites. Research has shown that aluminium material forms the larger parts of the entire body of vehicles due to the installed integrated safety package and concise engine size. Non-heat-treated $\mathrm{Al}-\mathrm{Mg} 5 \mathrm{xx}$ alloy and heat treatable $\mathrm{Al}-\mathrm{Mg}-\mathrm{Si} 6 \mathrm{xx}$ remain the main alloy of aluminium material used. Al-5xx has been widely employed due to its distinctive mechanical strength and corrosion resistance prowess, while Al-6xx has been used mostly for vehicle body formability. Al-8 xx has also found its application as radiator reflector (fin and foil) to guide against heat loss, which might cause an increase in fuel consumption and excess release of $\mathrm{CO}_{2}$ emission [16].

Adebisi et al., 2011 [17] research the emerging potential of the metal composite in the global market, the authors realized an increase in the usage of MMC ranging from 4.1 million in 2007 to 4.4 million kilograms for 2008 in which the automobile components had the largest share of about 2.4 million. Till date, the utilization of the MMC in auto-component is dynamically increasing and topping the global MMC market due to its sustainable properties that are absent in other contemporaries. Brake rotor made of aluminium metal matrix composite AMMCs, an essential auto-component was observed with weight reduction to high efficiency of about $60 \%$ compared to mild steel and iron. Hence, identified with high marketability, better performance, and low cost of maintenance.

The addition of nano ceramic nitrides by the two-step stir casting process has emerged as a novel niche of research in the recent dispensation. These ceramic reinforcement materials in composite development play a distinctive role in affecting and complimenting the properties of the primary aluminium material. They are characterized by good thermal stability, excellent hardness and tensile strength, and good corrosion resistance properties [18-20]. Although, the inclusion of the inorganic ceramic hard particulates often tradeoff with the inherent electrical conductivity of the aluminium and render the composite developed with high resistivity. However, the electrical resistance can be minimized by developing a porous-free composite.

The development of aluminium based composite to improve the corrosion resistance and ensure thermal stability at a high temperature is the focus of this research. This novel research will, therefore, fabricate AA8011- $\mathrm{Si}_{3} \mathrm{~N}_{4}$ composite via stir casting route for automobile application and assess its corrosion resistance performance, electrical response, and thermal stability behavior at high temperatures.

\section{Materials and methods}

\subsection{Materials}

The high-grade aluminium AA8011 matrix material with major alloying elements of iron (Fe) and Silicon ( $\mathrm{Si}$ ) was employed in this novel research work and the alloying compositions are shown in Table 1. The particulate reinforcing material utilized was inorganic nano Silicon nitride $\left(\mathrm{Si}_{3} \mathrm{~N}_{4}\right)$ of size $50 \mathrm{~nm}$. The selection of AA8011 as the base material can be attributed to its exceptional properties as a new grade of aluminium alloy that compliments the properties of other alloys of aluminium.

\subsection{Methods}

The methodological flow of this research work is presented in Fig. 1. The flow entails the selection of materials for the fabrication of composite, characterization, and analyses of composite material properties to achieve the objective(s) of this novel research.

\subsubsection{Development of $A A 8011$ with $\mathrm{Si}_{3} \mathrm{~N}_{4}$ via two-step stir casting process}

"Aluminium (AA8011) alloy as a metal matrix, and $\mathrm{Si}_{3} \mathrm{~N}_{4}$, as ceramic particulates are required to produce the composites having $5,10,15$, and 20 wt percent particulates. Initially, the furnace was heated, and the weighted quantity of aluminum billet was melted to the desired superheating temperature of $800{ }^{\circ} \mathrm{C}$ (above the melting temperature of the alloy) using the charged furnace in a graphite crucible for $5 \mathrm{~h}$ the required quantity of $\mathrm{Si}_{3} \mathrm{~N}_{4}$ particulates was preheated to around $450{ }^{\circ} \mathrm{C}$ in an oven to oxidized and degas surface layer thereby ensuring improved wettability, uniform dispersion, and reduced porosity. The molten materials were taken in a crucible and transferred to another crucible in the separate stirring arrangement. The graphite stirrer is lowered into the melt pool and slowly stirred to obtain vortex. Thereafter, the pre-heated $\mathrm{Si}_{3} \mathrm{~N}_{4}$ was added to the molten metal with the temperature maintained at $700{ }^{\circ} \mathrm{C} .2 \%$ by weight of Magnesium powder was added to ensure good wettability with continuous stirring at a speed of 200-500 rpm for $10 \mathrm{~min}$. The stirring is continued further for $5 \mathrm{~min}$ till a uniform mixture was achieved. The resulting molten composite from the stirring arrangement was withdrawn and poured at a temperature of $650{ }^{\circ} \mathrm{C}$ into the cylindrical sand molds of $200 \times 30$ $\mathrm{mm}$ size without any delay. Adequate caution was taken to ensure the complete solidification of the melt in the mold. Upon the complete solidification, the composites were withdrawn from the mold and machined precisely to required shape and sizes" [21].

\subsubsection{Analysis of the thermal behavior of $A A 8011-\mathrm{Si}_{3} \mathrm{~N}_{4}$ composite}

The thermal properties of the fabricated AA8011- $\mathrm{Si}_{3} \mathrm{~N}_{4}$ composite were examined using PerkinElmer TGA (TGA 4000) and NETZSCH DTA 404 PC respectively. The samples for the thermogravimetric analysis (TGA) were analyzed in a controlled inert nitrogen environment in the temperature range of $30 \mathrm{C}$ to $900 \mathrm{C}$ at a scan rate of $20 \mathrm{Cmin}^{-1}$ according to ASTM E2550 [22].

While TGA was used to study the mass loss of the composite as a function of temperature, the differential thermal analysis (DTA) was utilized to establish the solid-liquid transition (melting point) as a function of temperature ranging from $30 \mathrm{C}$ to $700 \mathrm{C}$ at a scan

Table 1

Alloying (elemental) composition of the AA8011.

\begin{tabular}{llllllllll}
\hline $\mathrm{Fe}$ & $\mathrm{Si}$ & $\mathrm{Mn}$ & $\mathrm{Cu}$ & $\mathrm{Zn}$ & $\mathrm{Ti}$ & $\mathrm{Mg}$ & $\mathrm{Pb}$ & $\mathrm{Sn}$ & $\mathrm{Al}$ \\
\hline 0.68 & 0.52 & 0.09 & 0.16 & 0.23 & 0.02 & 0.45 & 0.01 & -0.00 & 97.72 \\
\hline
\end{tabular}




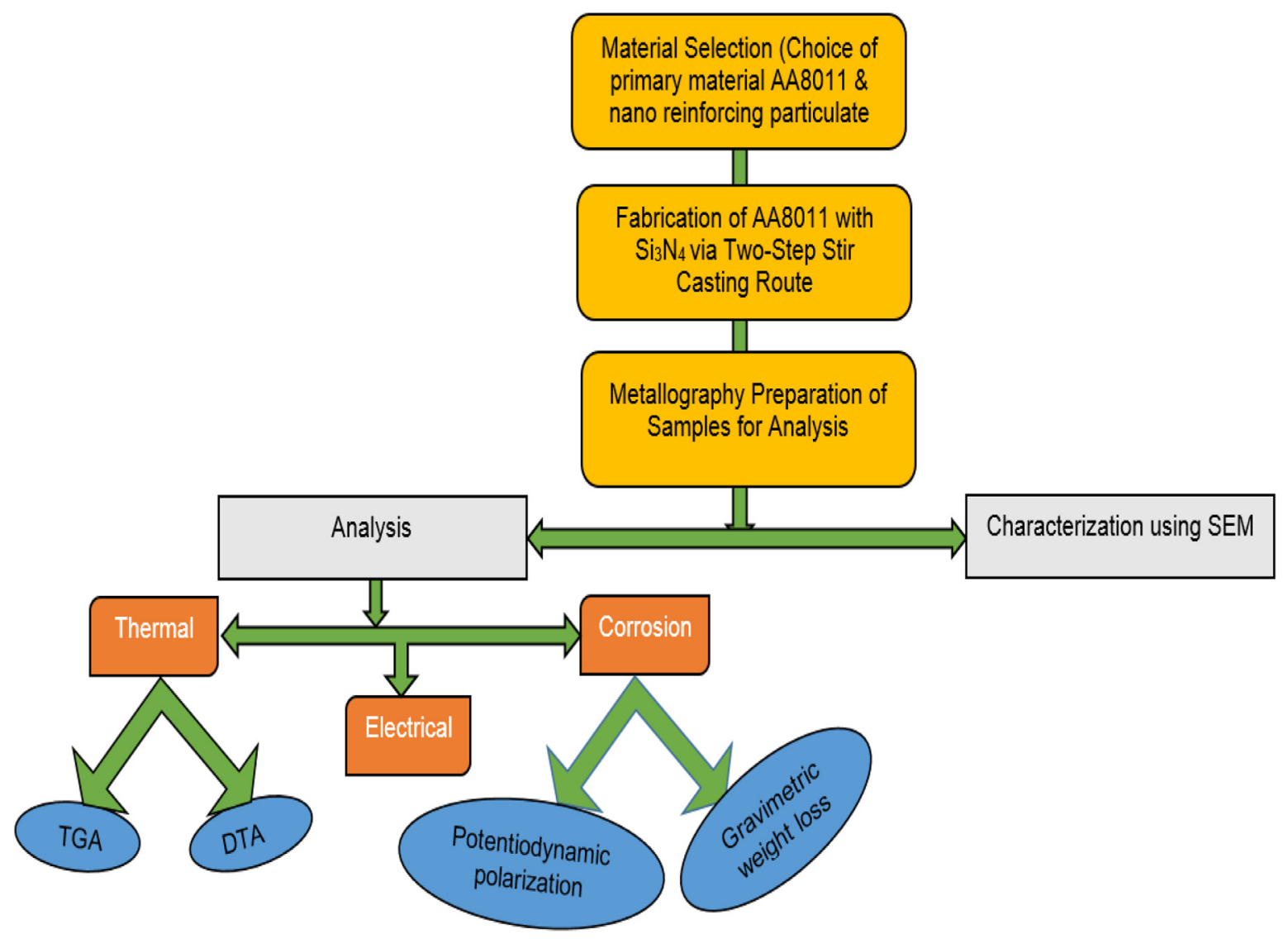

Fig. 1. Schematic flow chat of the methodology.

rate of $20 \mathrm{Cmin}^{-1}$.

\subsubsection{Analysis of the electrical response of $\mathrm{AA8011}-\mathrm{Si}_{3} \mathrm{~N}_{4}$}

The electrical resistivity of the developed composite was examined using a four-point probe ohm meter HP2662, China. The digital micro-sensitive four-point probe meter with a current source of $100 \mathrm{~mA}$ measures as low as possible the resistivity of the composite. The representative samples were dimensioned to $20 \times 20 \mathrm{~mm}$ size. The conductivity of the material was obtained by inverse resistivity.

\subsubsection{Corrosion behavior of $\mathrm{AA8011}-\mathrm{Si}_{3} \mathrm{~N}_{4}$ composite}

2.2.4.1. A corrosion study via potentiodynamic polarization route. For all the corrosion test, the samples were cut to $15 \mathrm{~mm} \times 15 \mathrm{~mm}$ dimension size, metallographically prepared by grinding, polishing, and then analyzed at ambient temperature with about $2.0 \mathrm{~cm}^{2}$ surface area exposed to the simulated seawater medium (3.65\% $\mathrm{NaCl}$ ). In this test, $\mathrm{Ag} / \mathrm{AgCl}$ was employed as the reference electrode, platinum rod as the counter electrode, and $\mathrm{AA8011}-\mathrm{Si}_{3} \mathrm{~N}_{4}$ serves as the working electrode on the potentiostat PGSTAT302 N equipped with 2.1 version of NOVA software. The electrochemical corrosion analysis which entails the Tafel extrapolation was performed at a scan rate of $0.0015 \mathrm{~V} \mathrm{~s}^{-1}$ with the polarization potential from $-1.5 \mathrm{~V}$ to the maximum of $+\mathbf{1 . 5} \mathrm{V}$. The analyses were conducted in the present and absent of reinforcing nanomaterial.

2.2.4.2. B. corrosion study via gravimetric (weight loss method) measurement. For gravimetric weight loss analysis, the dimensioned samples size of $15 \mathrm{~mm} \times 15 \mathrm{~mm}$ was cleaned with ethanol, dried in acetone, and weighed using a digital weighing balance to obtain the initial weight of each coupon before immersion into the simulated corroded environment of $3.65 \% \mathrm{NaCl}$. The corrosion process was examined for a total of $168 \mathrm{~h}$ ( 7 days) in an interval of $24 \mathrm{~h}$. At the end of every $24 \mathrm{~h}$, the samples were rinsed with water, degrease in ethanol, dried in acetone, and weighed to obtain the final weight of the samples. ASTM-G67-80 testing standards for the weight loss process were employed for this research work [22]. From the data obtained, the corrosion rate of the reinforced composite was calculated according to Refs. $[23,24]$ while the inhibitive efficiency with Eq.n (1).

Inhibitive Efficiency $(\%)=\frac{C r a-C r s}{C r a} \times 100$

where $\mathrm{Cr}_{\mathrm{a}}$ is the corrosion rate of the unreinforced AA8011 alloy, $\mathrm{Cr}_{\mathrm{s}}$ is the corrosion rate of the nano $\mathrm{Si}_{3} \mathrm{~N}_{4}$ reinforcing material.

\subsubsection{Micrographs of the corroded surfaces of AA8011-Si ${ }_{3} \mathrm{~N}_{4}$ composite}

This research work employed high-performance SEM VEGA 3 TESCAN, Brno, Czech Republic equipped with EDS, Oxford instrument, Oxfordshire UK to characterize the corroded surfaces after potential polarization tests.

\section{Results and discussion}

\subsection{Thermal behavior of $\mathrm{AA} 8011-\mathrm{Si}_{3} \mathrm{~N}_{4}$ composite}

The investigation of the thermal response of the unreinforced AA8011 and the developed AA8011- $\mathrm{Si}_{3} \mathrm{~N}_{4}$ composites has been accomplished using a thermogravimetric analyzer (TGA) and 
differential thermal analyzer (DTA). Figs. 2-6 presents the percentage change in weight of the materials as a function of the temperature ranging from $30^{\circ} \mathrm{C}$ to $900^{\circ} \mathrm{C}$ at a constant heating rate of $20^{\circ} \mathrm{C} / \mathrm{min}$. TGA is employed to ascertain the thermal stability of the developed composite under an inert nitrogen environment with a constant heating rate while the mass change is examined. The results of the thermograms revealed that the incorporated Nano $\mathrm{Si}_{3} \mathrm{~N}_{4}$ has enhanced the thermal stability of the aluminium matrix. The increase in the percentage reinforcement of the $\mathrm{Si}_{3} \mathrm{~N}_{4}$ addition aid the reduction in the mass loss of material as the temperature progresses from $30^{\circ} \mathrm{C}$ to $900^{\circ} \mathrm{C}$. The percentage mass loss rate of the unreinforced AA8011 was observed to be $26 \%$ in Fig. 2, this rate of material loss reduces with the incorporation of $\mathrm{Si}_{3} \mathrm{~N}_{4}$ as seen in $5 \mathrm{wt} \%$ reinforcement with $25.5 \%$ mass loss. At $10 \mathrm{wt}$ $\%-\mathrm{Si}_{3} \mathrm{~N}_{4}$, the material loss decreases drastically to about $14.5 \%$ and the best reduction of mass loss was observed in $20 \mathrm{wt} \%$ particulates with an $11.6 \%$ loss. Therefore, it is not out of context if stated that the inclusion of the Nano $\mathrm{Si}_{3} \mathrm{~N}_{4}$ helped in material saving by enhancing the reduction of mass loss.

This Nanoceramic $\mathrm{Si}_{3} \mathrm{~N}_{4}$ acted as a barrier to the diffusion path of the decomposed product. Hence, 20 wt\% reinforcement shows a $14.4 \%$ decrease in mass loss rate which is more than twice below the mass loss rate of the unreinforced AA8011 alloy. Also, the inclusion of $\mathrm{Si}_{3} \mathrm{~N}_{4}$ increases the decomposition temperature of the composite thereby making it thermally stable in the nitrogen environment at the higher temperature. It is evident from the plot in Figs. 3-6 that as the percentage weight of $\mathrm{Si}_{3} \mathrm{~N}_{4}$ reinforcement increases, the thermal stability of the composite increases, and negligible mass loss was observed. Hence, the increase in thermal stability could be ascribed to the bonding interaction and strong adhesion between the Nano $\mathrm{Si}_{3} \mathrm{~N}_{4}$ and the AA8011 matrix [25]. affirmed that a thermally stable material is expected to possess little or negligible mass loss and minimal or no slope in the TGA curve, this, therefore, means that composite with $20 \mathrm{wt} \%$ reinforcement is more thermally stable than others as it shows little slope in the TGA plot and also the mass loss is twice lower than the unreinforced AA8011 alloy. Hence, one can say that the change is significant looking carefully at the variation in the phase transformation plot as revealed in Fig. 7 .

The unreinforced AA8011 matrix and the developed composite of $\mathrm{AA} 8011-\mathrm{Si}_{3} \mathrm{~N}_{4}$ were examined using DTA as seen in Fig. 7. The result shows an endothermic peak at $661.1^{\circ} \mathrm{C}$ for an unreinforced AA8011 which indicates the point of solid-liquid transition i. e melting temperature of the alloy. The incorporation of the

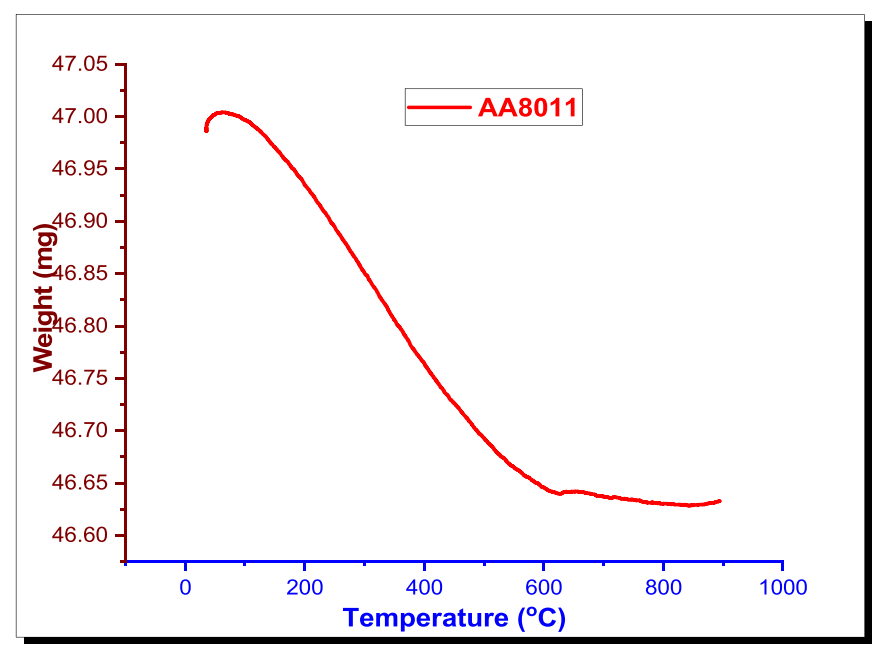

Fig. 2. Thermogravimetric analysis (TGA) result of the as-cast AA8011.

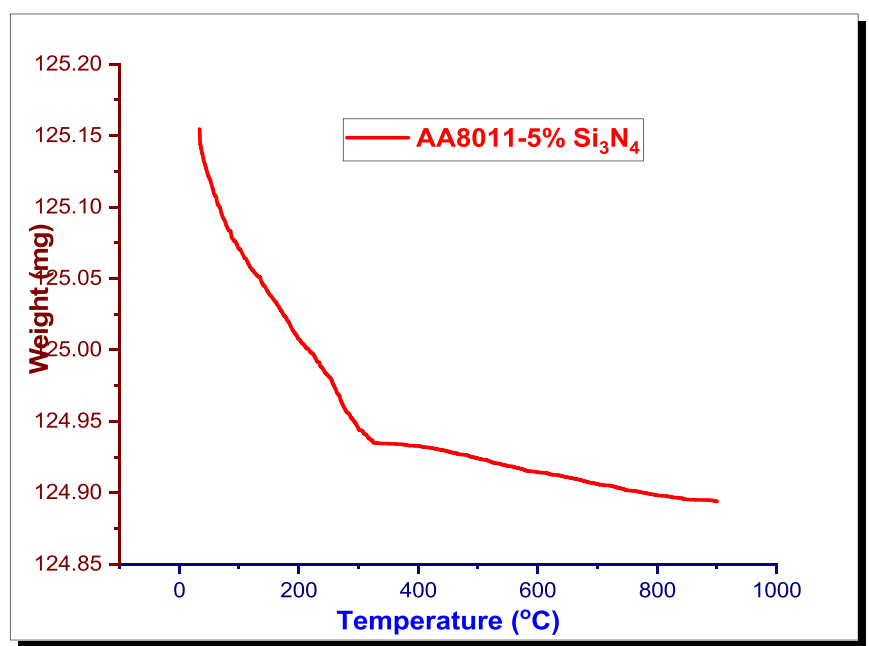

Fig. 3. Thermogravimetric analysis (TGA) result of the developed AA8011-5\% $\mathrm{Si}_{3} \mathrm{~N}_{4}$.

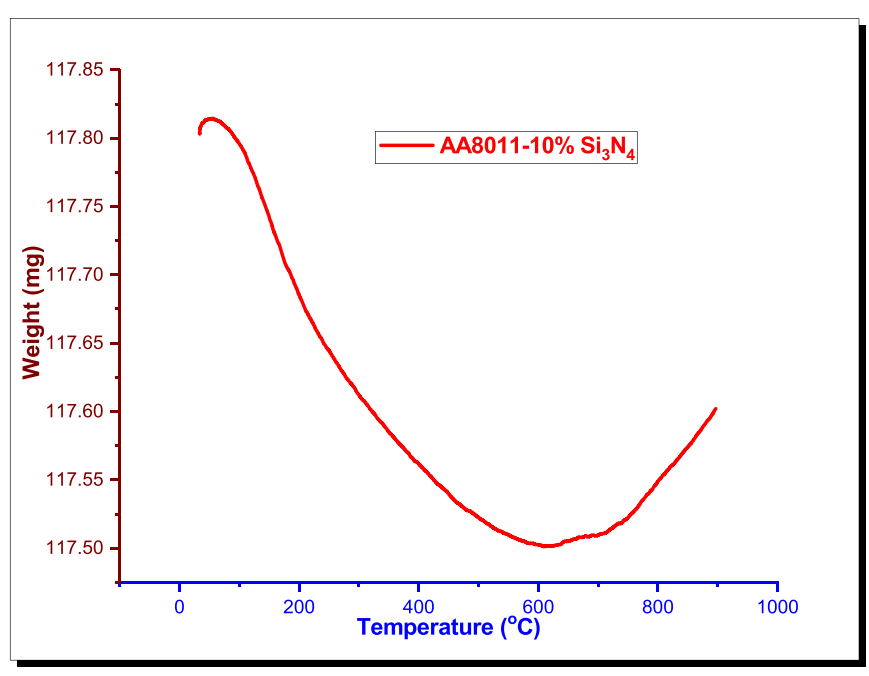

Fig. 4. Thermogravimetric analysis (TGA) result of the developed AA8011-10\% $\mathrm{Si}_{3} \mathrm{~N}_{4}$.

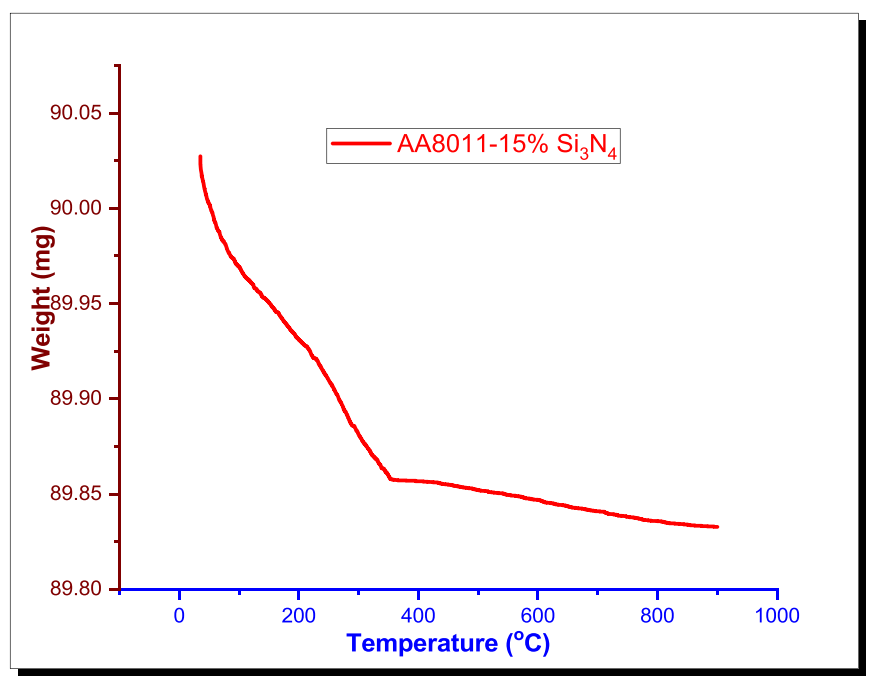

Fig. 5. Thermogravimetric analysis (TGA) result of the developed AA8011-15\% $\mathrm{Si}_{3} \mathrm{~N}_{4}$. 


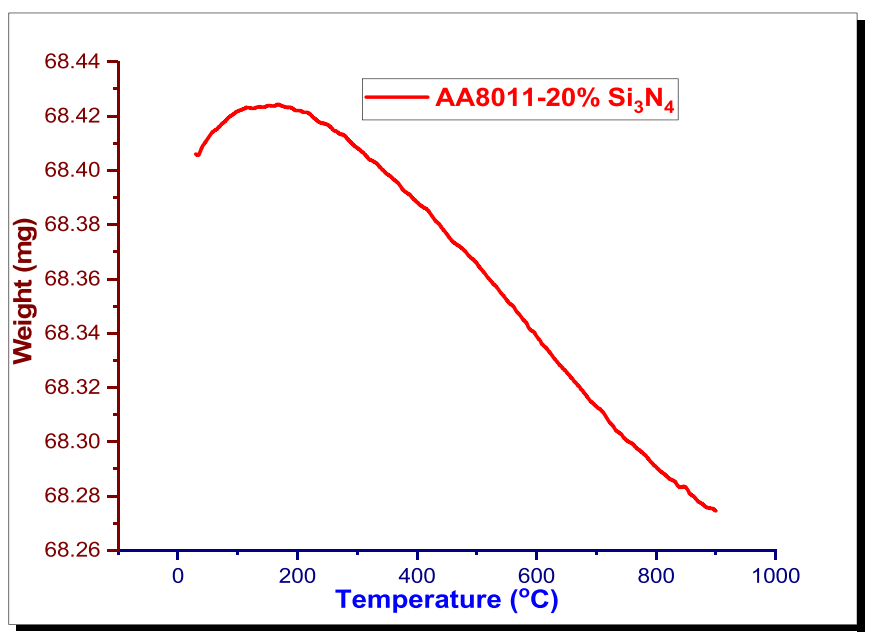

Fig. 6. Thermogravimetric analysis (TGA) result of the developed AA8011- $20 \% \mathrm{Si}_{3} \mathrm{~N}_{4}$.

Nanoceramic $\mathrm{Si}_{3} \mathrm{~N}_{4}$ increases the melting temperature $(\mathrm{Tm})$ of the composite. However, the improvement of the melting temperature is a function of the percentage weight fraction of the second discontinuous phase that was introduced into the melt pool of the AA8011 matrix. The composite with $20 \%$ reinforcement possessed an improved melting temperature of $668.8{ }^{\circ} \mathrm{C}$ which is better compared to the unreinforced alloy. The evaluation of these AA8011- $\mathrm{Si}_{3} \mathrm{~N}_{4}$ composite reveals that the $\mathrm{Si}_{3} \mathrm{~N}_{4}$ inclusion significantly played a role in improving the solid transition temperature.

\subsection{Electrical response (conductivity, resistivity, and IACS) of $\mathrm{AA} 8011-\mathrm{Si}_{3} \mathrm{~N}_{4}$}

The electrical responses viz; conductivity, IACS, and resistivity of the AA8011 reinforced non-conductive nano ceramic $\mathrm{Si}_{3} \mathrm{~N}_{4}$ are presented in Fig. 8. As observed in the plot, the resistivity of the AA8011- $\mathrm{Si}_{3} \mathrm{~N}_{4}$ composite increases with the increase in the $\mathrm{Si}_{3} \mathrm{~N}_{4}$ inclusion. The unreinforced alloy AA8011 was examined to have a resistivity of $4.28 \times 10^{-6} \Omega \mathrm{m}$ which increases to $4.38 \times 10^{-6} \Omega \mathrm{m}$ at

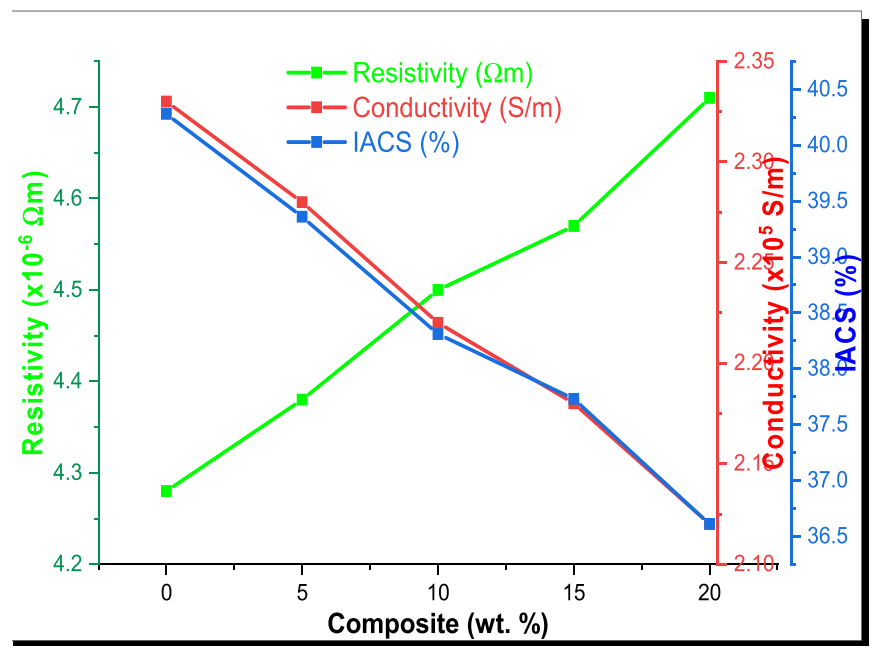

Fig. 8. The Electrical Plot showing the Resistivity, Conductivity, and IACS.

$5 \% \mathrm{Si}_{3} \mathrm{~N}_{4}$ reinforcement, and the highest resistivity of $4.71 \times 10^{-6}$ $\Omega \mathrm{m}$ was obtained for $20 \%$ reinforcement. The continuous progression of the electrical resistance nature of the composite as a function of the increase in the $\mathrm{Si}_{3} \mathrm{~N}_{4}$ weight fraction resulted due to the discontinuity or scattering of the free electron charge movement posed by the inclusion of the non-conductive material [26]. Cao et al., 2017 stated that the electrical resistivity of a material is a micro-sensitive property in which the slight change or modification in the microstructure by particulate addition often influences the electrical resistance of such composite material. This, therefore, means that the size, nature, weight percentage of the reinforcing particulate and the degree of uniform dispersion in the lattice of the continuous conductive AA8011 play an essential role in enhancing the resistivity of the composite. Hence, in this research, the even distribution of the non-conductive nano $\mathrm{Si}_{3} \mathrm{~N}_{4}$ in the melt-pool of the conductive AA8011 and the wettability achieved as a result of the two-stir casting process parameters is responsible for the smaller resistivity. The even dispersion of nanomaterial with an insignificant micro-porous site assists in reducing the scattering of

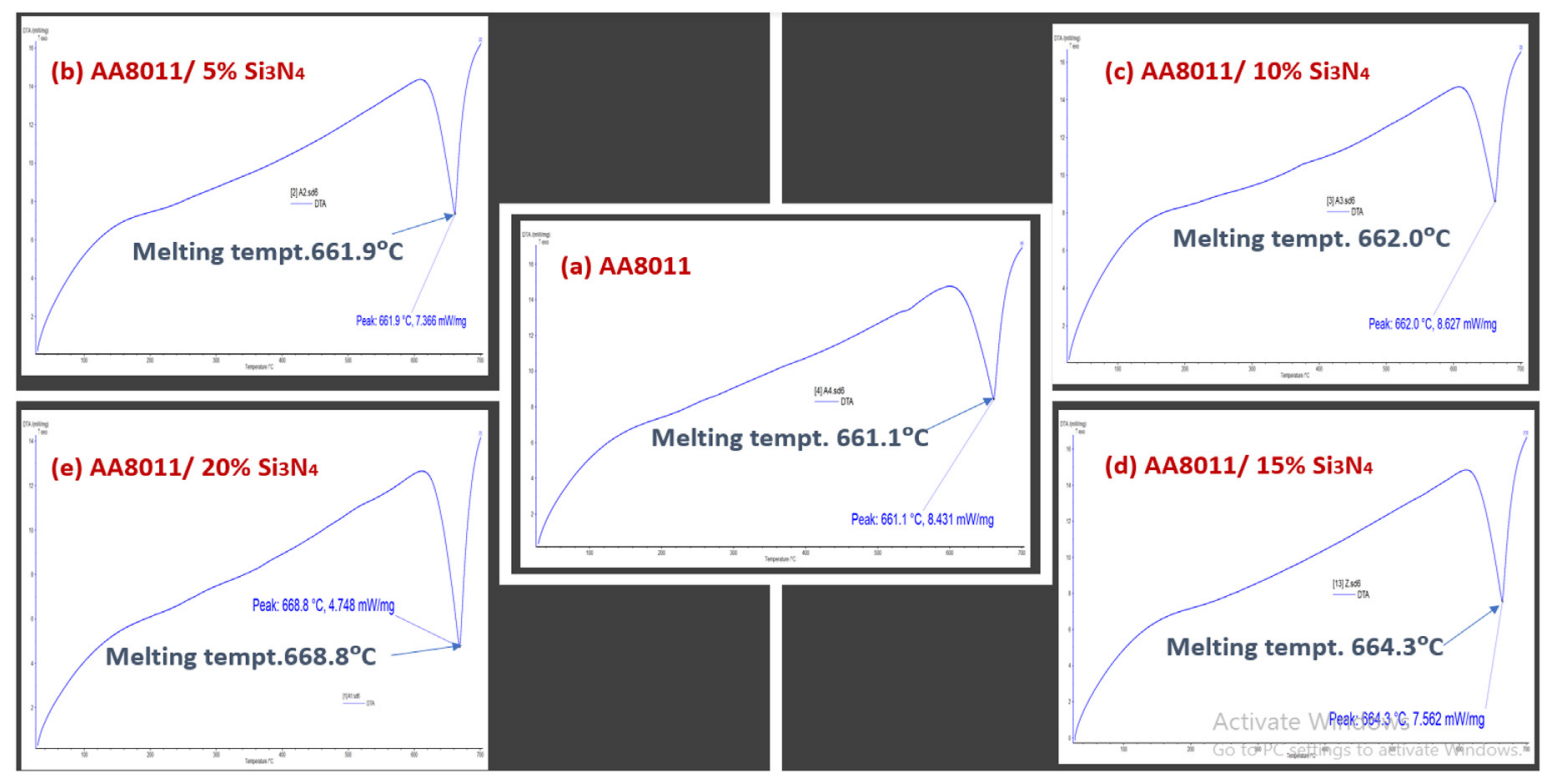

Fig. 7. The Phase Transformation of the Developed AA8011- $\mathrm{Si}_{3} \mathrm{~N}_{4}$ Composite by. 
the electron which leads to low resistivity. The presence of the micro-pore space in the AA8011-20 wt\% $\mathrm{Si}_{3} \mathrm{~N}_{4}$ increases the distortion of the inherent electron movement thereby resulted in higher electrical resistance. Likewise, the inclusion of the inorganic non-conductive $\mathrm{Si}_{3} \mathrm{~N}_{4}$ causes regression in the electrical conductivity of AA8011. As shown in Fig. 8, the least electrical conductivity of $2.12 \times 10^{5}$ (36.61\% IACS) was possessed by the AA8011-20 wt\% $\mathrm{Si}_{3} \mathrm{~N}_{4}$ composite due to the hindrance against the free flow of electron charge, leading to an enhanced higher electrical resistance. According to Ref. [27] Zhukov et al., 2019, particulate inclusions usually acted as a barrier to free-electron pass which invariably reduces the electrical conductivity of the base material. hence, the insignificant reduction in the electrical conductivity of AA8011 with the inclusion of $\mathrm{Si}_{3} \mathrm{~N}_{4}$ can be attributed to the great average distance between the $\mathrm{Si}_{3} \mathrm{~N}_{4}$ particulate to the distance of the free flow of electrons. This was made possible due to the absence or minimal occurrence of porosity in the composite that might reduce the distance and influence great electron scattering.

\subsection{Corrosion behavior of $A A 8011-S_{3} N_{4}$ composite}

\subsubsection{Corrosion study via potentiodynamic polarization route}

Fig. 9 presents the electrochemical behavior of the developed AA8011- $\mathrm{Si}_{3} \mathrm{~N}_{4}$ which was experimented in the simulated artificial seawater medium of $3.65 \% \mathrm{NaCl}$. The outcome of the experimental studies shows that the developed composite (AA8011- $\mathrm{XSi}_{3} \mathrm{~N}_{4}$ ) was exceptional in resisting the corrosion attack posed by the chloride $\left(\mathrm{Cl}^{-}\right)$ion compared to the unreinforced alloy (AA8011). The corrosion resistance value of the reinforced alloy was observed to have high potential over the unreinforced matrix alloy and the potential increases with an increase in the nano $\mathrm{Si}_{3} \mathrm{~N}_{4}$ addition. Naturally, aluminium forms a passive oxide film when exposed to the clean environment (moisture) but these thin film layers are broken when exposed to the aggrieved environment such as the $\mathrm{Cl}^{-}, \mathrm{SO}_{4}^{2-}, \mathrm{NO}_{3}^{-}$ thereby exposing the aluminium to severe corrosion attack. However, the presence of the inert nano ceramic $\mathrm{Si}_{3} \mathrm{~N}_{4}$ which barely deteriorates in a corroded environment modifies the microstructure of the matrix to block any form of corrosion initiation and form thick passive layers on the surface of the aluminium alloy against corrosion attack.

Comparing the degree or percentage weight reinforcement performance of the developed composite, the composite with $20 \%$ $\mathrm{Si}_{3} \mathrm{~N}_{4}$ particulate performs excellently well in retarding corrosion attack than the $0 \%, 5 \%, 10 \%$, and $15 \% \mathrm{Si}_{3} \mathrm{~N}_{4}$ addition. The as-cast

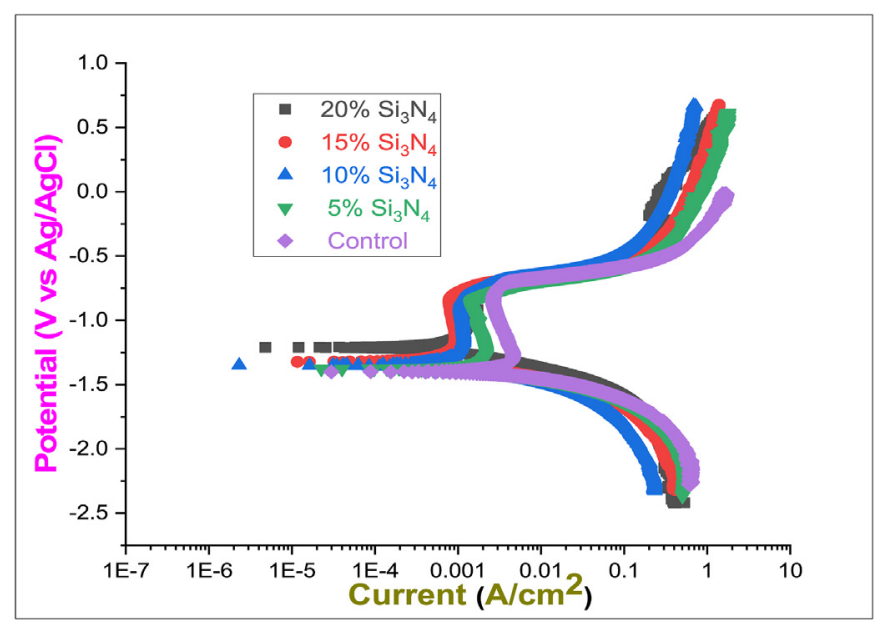

Fig. 9. Polarization curve of $\mathrm{AA} 8011-\mathrm{Si}_{3} \mathrm{~N}_{4}$ composite.
AA8011 had a potential of $-1.4011 \mathrm{~V}$, the current density of $3.89 \times 10^{-4} \mathrm{~A} / \mathrm{cm}^{2}$, the least linear polarization resistance of $134.46 \Omega$, and the highest corrosion rate of $4.5 \mathrm{~mm} / \mathrm{yr}$ which was due to the exposure of the metal surface to the $\mathrm{Cl}^{-}$ion that damage the inherent thin-film oxide formed on the AA8011 surface without possible regeneration.

From the extrapolation shown in Table 2, the least corrosion density $i_{\text {corr }}$ of $6.54 \times 10^{-5} \mathrm{~A} / \mathrm{cm}^{2}$, the corrosion rate of $0.9575 \mathrm{~mm} /$ $\mathrm{yr}$, and the highest polarization resistance of $4941.4 \Omega$ were observed with $20 \% \mathrm{Si}_{3} \mathrm{~N}_{4}$ composite. Hence, significant drift towards the region of more positive potential was observed for AA8011-20\% $\mathrm{Si}_{3} \mathrm{~N}_{4}$. Therefore, it is expedient to mention that the shift of the potential to the positive direction as the weight percent of the nano $\mathrm{Si}_{3} \mathrm{~N}_{4}$ inclusion increases depicted the formation of the passivated film layers. In a nutshell, the potential of the developed composite for the activities of each of the reinforcement weight composition viz; $5 \%, 10 \%, 15 \%$, and $20 \% \mathrm{Si}_{3} \mathrm{~N}_{4}$ gave different passivation level.

Suresh et al., 2018 [28] examined the corrosion behavior of $\mathrm{Al} 7075$ reinforced with nano-ceramic $\mathrm{SiC} / \mathrm{Al}_{2} \mathrm{O}_{3}$ in $3.5 \% \mathrm{NaCl}$ medium. The composites were developed via stir casting process to contain $1 \%, 2 \%, 3 \%$, and $4 \%$ nanomaterials. The outcome of the findings depicted that the inert nature of the nanoceramic inclusion in the melt pool of Al7075 functions as an insulator to corrosion attack in the simulated deteriorating medium. Throughout their experiment, the corrosion rate decreases with the percentage rise in $\mathrm{SiC} / \mathrm{Al}_{2} \mathrm{O}_{3}$ content.

The surface degradation of the composite samples subjected to the artificial simulated seawater environment $(3.65 \% \mathrm{NaCl})$ was evaluated using a scanning electron microscope (SEM) as shown in Fig. 10. The SEM image of the corroded primary alloy material (AA8011) revealed more intense pitting and cracking locations compared to the reinforced $A A 8011-\mathrm{XSi}_{3} \mathrm{~N}_{4}$. The degree of the corrosion rate depends on the permissible level of the chloride ion which infiltrates into the grain boundaries of the materials thereby initiating a corrosion site either by pitting or localized. It was generally observed that the even distribution of the nano $\mathrm{Si}_{3} \mathrm{~N}_{4}$ is a function of the extent of the surface deterioration of the developed sample in the aggrieved environment, this depicted that the better the dispersion of the inert insulating nano $\mathrm{xSi}_{3} \mathrm{~N}_{4}$, the more protected the composite in the chloride medium. From Fig. 10, the surface of AA8011 was characterized with deep pits leading to an induced crack formation in which the cracks aid the continuous removal of material in the form of flakes. From the micrographs, it is obvious that the presence of the reinforcing particulate reduces the corrosion attack by increasing the surface coverage thereby decreasing the corrosion potential. As the weight percent of the reinforcing material increases from $5 \%$ to $20 \% \mathrm{Si}_{3} \mathrm{~N}_{4}$, the pitting corrosion decreases, and at $20 \%$ of $\mathrm{Si}_{3} \mathrm{~N}_{4}$, there exists no obvious noticeable pitting or any other forms of corrosion.

\subsubsection{Corrosion study via gravimetric (weight loss method) measurement}

The corrosion behavior of materials has been established to be studied via different routes including the weight-loss gravimetric measurement. This method examines the corrosion of metals in an immersion medium over a certain duration of time either in minutes, hours, days, or months. In this research, weight loss was studied to investigate the corrosion process of AA8011- $\mathrm{XSi}_{3} \mathrm{~N}_{4}$ composite in the simulated chloride medium for a total of $168 \mathrm{~h} \mathrm{(7}$ days). This process entails the initial weight measurement of the representative sample (coupon) before immersion and the final weight sample after immersion in the sequence of $24,48,72,96$, 120,144 , and $168 \mathrm{~h}$ respectively to obtain the weight loss. Fig. 11 presents the progression of the weight loss of $\mathrm{AA} 8011-\mathrm{Si}_{3} \mathrm{~N}_{4}$ 
Table 2

Tafel extrapolation of the AA8011- $\mathrm{Si}_{3} \mathrm{~N}_{4}$ composite.

\begin{tabular}{|c|c|c|c|c|}
\hline Specimen & Corrosion Potential (V) & Current Density $\left(\mathrm{A} / \mathrm{cm}^{2}\right)$ & $\mathrm{L} \mathrm{R}_{\mathrm{P}}(\Omega)$ & $\begin{array}{l}\text { Corrosion } \\
\text { Rate }(\mathrm{mm} / \mathrm{yr})\end{array}$ \\
\hline AA8011 (as-cast) & -1.4011 & $3.89 \times 10^{-4}$ & 134.46 & 4.5149 \\
\hline AA8011-5\% $\mathrm{Si}_{3} \mathrm{~N}_{4}$ & -1.3802 & $3.18 \times 10^{-4}$ & 139.20 & 3.6965 \\
\hline AA8011-10\% $\mathrm{Si}_{3} \mathrm{~N}_{4}$ & -1.3151 & $2.96 \times 10^{-4}$ & 146.51 & 3.4842 \\
\hline AA8011-15\% $\mathrm{Si}_{3} \mathrm{~N}_{4}$ & -1.2517 & $6.73 \times 10^{-5}$ & 4248.4 & 0.7826 \\
\hline AA8011-20\% $\mathrm{Si}_{3} \mathrm{~N}_{4}$ & -1.1692 & $6.54 \times 10^{-5}$ & 4941.4 & 0.7595 \\
\hline
\end{tabular}
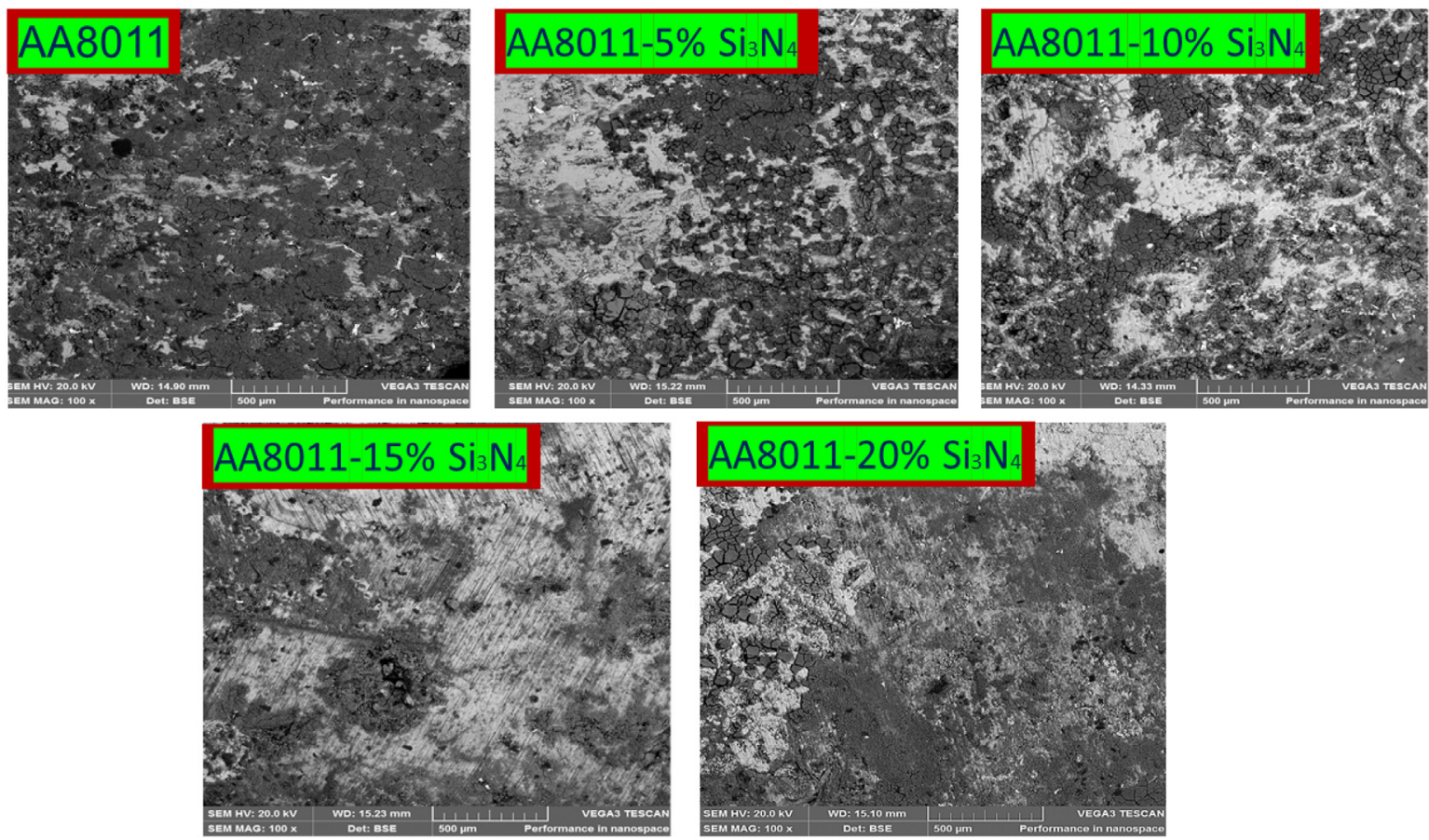

Fig. 10. SEM micrographs of the corroded surfaces of $A A 8011-\mathrm{Si}_{3} \mathrm{~N}_{4}$ composite after corrosion test

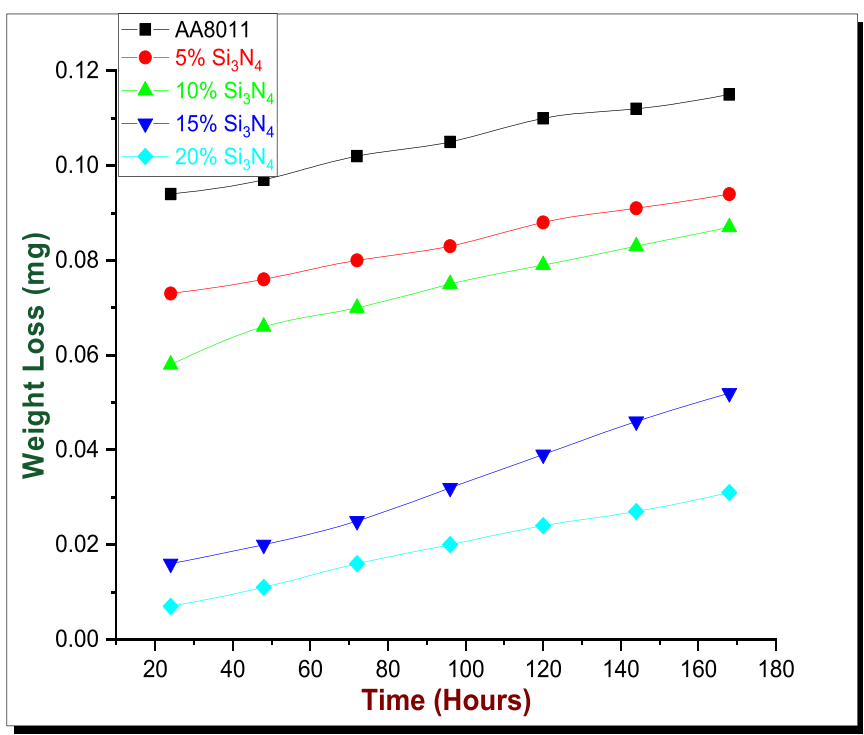

Fig. 11. Variation of weight loss as a function of time.

composite as a function of the immersion time intervals under the simulated artificial seawater medium of $3.65 \% \mathrm{NaCl}$ at an ambient room temperature of $25^{\circ} \mathrm{C}$. The outcome of the results revealed the reduction of mass loss as the weight percent of the reinforcing nano $\mathrm{Si}_{3} \mathrm{~N}_{4}$ increases. The mass loss of the composite samples was observed to be increasing consequentially as the immersion time increases but attain stability with minor material loss over a long duration due to the formation of protective oxide film layers in chloride medium. For all the reinforced samples, there is an obvious decrease in mass loss with the inclusion of the inert nano-nitride material which helps to form a strong protective barrier against corrosion attack. Hence, it can be summarized that the presence of $\mathrm{Si}_{3} \mathrm{~N}_{4}$ in the nucleation of the AA8011 matrix help to mitigate against deterioration.

Likewise, the rate at which the corrosion process of the composite occurs as a function of the immersion time in the simulated $\mathrm{NaCl}$ is presented in Fig. 12. It is evident from the plot that the corrosion rate decreases as the immersion time and the reinforcing $\mathrm{Si}_{3} \mathrm{~N}_{4}$ increases. The unreinforced AA8011 is susceptible to corrosion in chloride environment and this vulnerability induces the formation of pits and cracks leading to severe material loss. The permissible act of chloride diffusion is responsible for the high weight loss and corrosion rate experienced by the AA8011 alloy. The inert property of the nano ceramic $\mathrm{Si}_{3} \mathrm{~N}_{4}$ that makes it resistant to corrosion was seen to influence the composite to have a low corrosion rate, its positive effect increases as the content percentage increases from $5 \%$ to $20 \%$. Hence, the increase in the corrosion rate at the early stage (hours) of immersion is due to the aggressive 


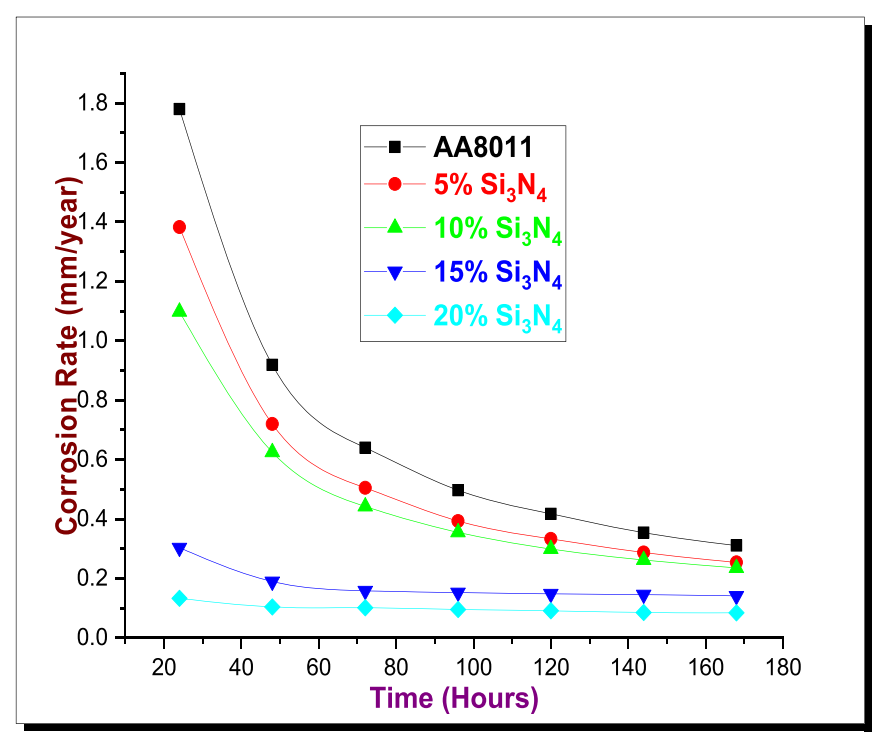

Fig. 12. The corrosion rate plot against time.

corrosion process that takes place at the interface of the sample before passivation.

The inhibitive efficiency potential and the surface coverage of the inorganic nano $\mathrm{Si}_{3} \mathrm{~N}_{4}$ particle as a function of the time intervals is presented in Figs. 13 and 14 to further support the experimental results as described in Figs. 11 and 12, while the summary of the Progression of the inhibitive efficiency and the surface coverage as a function of the inorganic nano inclusion is presented in Fig. 15. As seen in the curves, the inhibition effect of the inorganic material decreases as the time progresses from 24 to $168 \mathrm{~h}$, likewise, the surface coverage diminishes as well. Nonetheless, the inhibitive value and the surface protective coverage at the end of the $168 \mathrm{~h}$ (7th day) remain substantial for samples reinforced with $15 \%$ and $20 \% \mathrm{Si}_{3} \mathrm{~N}_{4}$ with the values of $54 \%, 73 \%$, and $0.548 \Theta, 0.730 \Theta$ respectively. This is an indication that not only the insulating nature of the nano ceramic $\mathrm{Si}_{3} \mathrm{~N}_{4}$ plays the vital role of savaging corrosion process but also the weight fraction which is heavily spread enough to block the site of corrosion initiation along the porous region. The

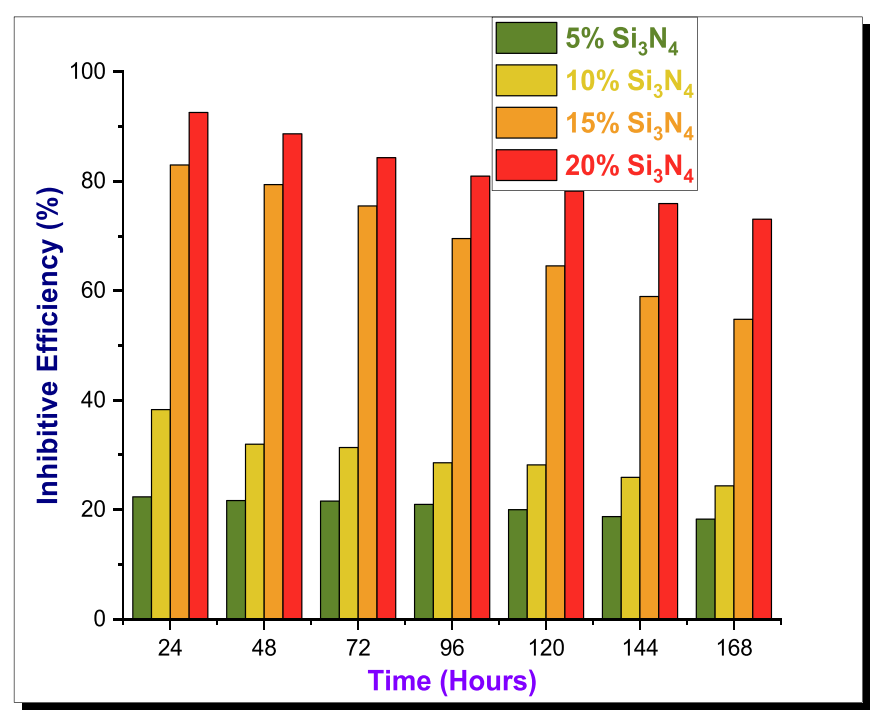

Fig. 13. Inhibitive efficiency versus time.

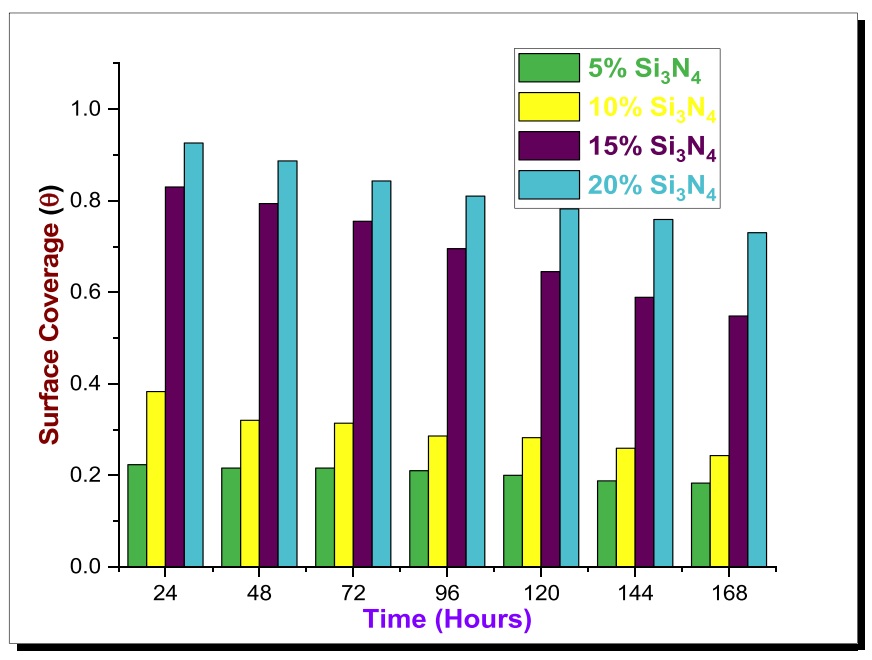

Fig. 14. The regression of the surface coverage with time increase.

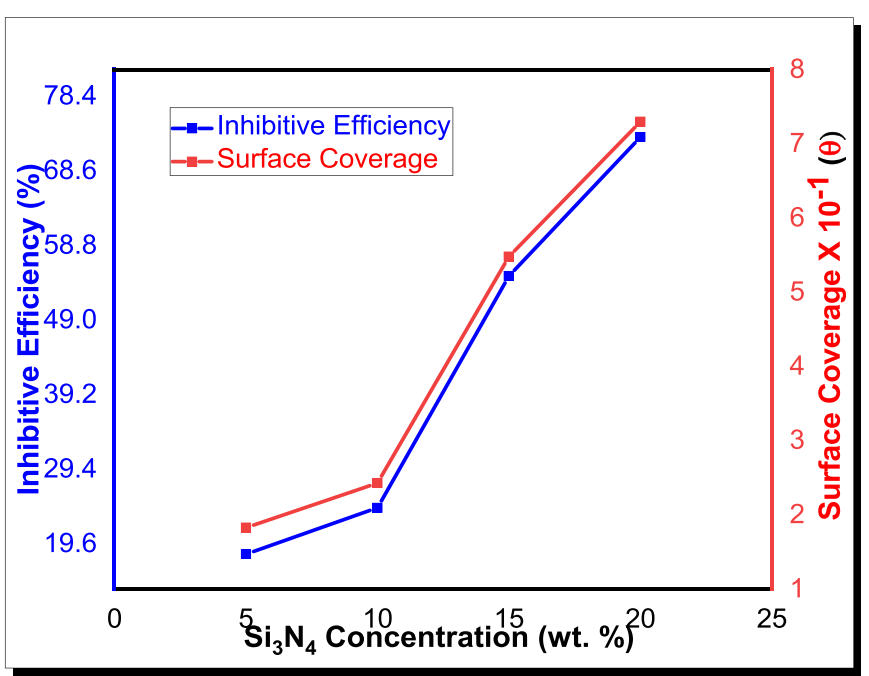

Fig. 15. The progression of the inhibitive efficiency of the developed AA8011- $\mathrm{Si}_{3} \mathrm{~N}_{4}$.

increase in the percentage reinforcement of the $\mathrm{Si}_{3} \mathrm{~N}_{4}$ enhanced the passivation thereby increases the protective coverage rendered to the surface area of the composite where corrosion might originate.

In summary to the extent to which the nano inorganic material $\mathrm{Si}_{3} \mathrm{~N}_{4}$ can mitigate corrosion, Fig. 15 revealed the variation of the percentage inhibitive effect and the surface coverage potential of the reinforcing $\mathrm{Si}_{3} \mathrm{~N}_{4}$ in the aggressive simulated seawater environment. At $5 \% \mathrm{Si}_{3} \mathrm{~N}_{4}$ reinforcement, the composite had an inhibitive value of $18.26 \%$ which increases to $24.34 \%, 54.78 \%$, and $73.04 \%$ for 10,15 , and $20 \% \mathrm{Si}_{3} \mathrm{~N}_{4}$ reinforcement respectively. This depicted that the increase in the reinforcing particulates leads to improved surface protection of the composite by inhibiting the corrosion posed by the chloride deteriorating medium.

\section{Conclusions}

1. AA8011-5 wt\% $\mathrm{Si}_{3} \mathrm{~N}_{4}, \mathrm{AA} 8011-10 \mathrm{wt} \% \mathrm{Si}_{3} \mathrm{~N}_{4}, \mathrm{AA8011-15} w \mathrm{wt} \%$ $\mathrm{Si}_{3} \mathrm{~N}_{4}, \mathrm{AA} 8011-20 \mathrm{wt} \% \mathrm{Si}_{3} \mathrm{~N}_{4}$ have been fabricated with less or no void via two-step stir casting process.

2. The corrosion study via the potentiodynamic electrochemical process revealed a decrease in corrosion rate with the percentage rise in the nano $\mathrm{Si}_{3} \mathrm{~N}_{4}$ inclusion and the composite with 
AA8011-20 wt\% $\mathrm{Si}_{3} \mathrm{~N}_{4}$ show the lowest corrosion rate of $0.7585 \mathrm{~mm} / \mathrm{yr}$.

3. The developed composite was observed to inhibit corrosion or rather resist corrosion attack posed by the chloride ion and the resistance potential increases with the percentage weight fraction of the reinforcing $\mathrm{Si}_{3} \mathrm{~N}_{4}$. This assertion was reached when the composite reinforced with $20 \mathrm{wt} \% \mathrm{Si}_{3} \mathrm{~N}_{4}$ had inhibitive efficiency of about $72 \%$ at the end of the $168 \mathrm{~h}$ via gravimetric weight loss measurement.

4. The thermogravimetric analysis (TGA) revealed a decrease in the material mass loss as a function of the increase in heating temperature. Excess material loss was established with the AA8011 matrix without reinforcement. However, DTA confirmed the thermal behavior of the developed composite by considering the solid-liquid transition of the material as a function of temperature rise. The outcome of the DTA analysis shows an improvement in the melting point temperature with the inclusion of highly fired ceramic $\mathrm{Si}_{3} \mathrm{~N}_{4}$.

5. The inclusion of inorganic non-conductive $\mathrm{Si}_{3} \mathrm{~N}_{4}$ particles hinders the continuous flow of electron in the AA8011 alloy, thereby decreasing the electrical conductivity potential of the matrix. Hence, the electrical resistivity of the composites increases with an increase in $\mathrm{Si}_{3} \mathrm{~N}_{4}$ addition.

\section{CRediT authorship contribution statement}

J. Fayomi: Conceptualization, Methodology, Formal analysis, Investigation, Data curation, Writing - original draft, Writing - review \& editing, Visualization. A.P.I. Popoola: Resources, Supervision, Funding acquisition. O.M. Popoola: Software, Supervision. O.S.I. Fayomi: Conceptualization, Validation, Investigation, Writing - review \& editing, Project administration.

\section{Declaration of competing interest}

The authors declare that they have no known competing financial interests or personal relationships that could have appeared to influence the work reported in this paper. Enclosed is a manuscript to be considered for publication in the Journal of alloys and Compounds. The research reported in this manuscript has been funded by Tshwane University of Technology Pretoria South Africa.

This serve to notify that the manuscript is original of the authors work and there is no conflict of interest of any kind regarding the manuscript on "The Appraisal of the Thermal Properties, Electrical Response, and Corrosion Resistance Performance of AA8011 reinforced Nano $\mathrm{Si}_{3} \mathrm{~N}_{4}$ for Automobile Application.

\section{Acknowledgment}

Department of Chemical, Metallurgical, and Materials Engineering, Surface Engineering Research Laboratory, Centre for Energy and Electric Power of the Tshwane University of Technology, and National Research Foundation South Africa are greatly acknowledged for their financial support, availability of equipment, and conducive research environment to conduct this novel research.

\section{References}

[1] K.K. Singh, S. Singh, A.K. Shrivastava, Study of tribological behaviour of silicon carbide-based aluminium metal matrix composites under dry and lubricated environment, Advances in Materials Science and Engineering 306 (2016) $1-11$.

[2] A.M. Razzaq, D.L. Majid, M.R. Ishak, U.M. Basheer, Effect of fly ash addition on the physical and mechanical properties of AA6063 alloy reinforcement, Metals 7 (477) (2017) 1-15, https://doi.org/10.3390/met7110477.

[3] M. Mariyappan, P. Sarangapani, G. Perumal, A. Sathiyamoorthi, Improvement in tribological behaviour of aluminium 356 hybrid metal matrix composites, J. Chem. Pharmaceut. Sci. Mater. 24 (2015) 805-810. In Proceedings of International Conference on Recent Advancement in Mechanical Engineering and Technology (ICRAMET' 15).

[4] M. Azadi, S. Safarloo, F. Loghman, R. Rasouli, Microstructural and thermal properties of piston aluminium alloy reinforced by nanoparticles, Proc.AIP Conf. (2018) 1-5, https://doi.org/10.14233/ajmc.2017.AJMC-P49, 020027.

[5] C.W. Kim, J.I. Cho, S.W. Choi, Y.C. Kim, C.S. Kang, The effect of alloying elements on thermal conductivity and casting characteristic in high-pressure die casting of aluminium alloy, in: Proceedings of 13th International Conference on Aluminium Alloys (ICAA13): TMS (The Minerals, Metals \& Materials Society), 2012.

[6] S.Y. Hur, K.T. Kim, Y.R. Yoo, Y.S. Kim, Effects of $\mathrm{NaCl}$ concentration and solution temperature on the galvanic corrosion between CFRP and AA7075T6, Corrosion Sci. Technol. 19 (2) (2020) 75-81.

[7] K. Asano, H. Yoneda, Y. Agari, M. Matsumuro, K. Higashi, Thermal and mechanical properties of aluminium alloy composite reinforced with potassium hexatitanate short fiber, Mater. Trans. 56 (1) (2015) 160-166.

[8] E.A.M. Shalaby, A.Y. Churyumov, D.H.A. Besisa, A. Daoud, M.T. Abou El-Khai, A comparative study of thermal conductivity and tribological behaviour of squeeze cast A359/AlN and A359/SiC composites, J. Mater. Eng. Perform. 26 (2017) 3079-3089.

[9] B.S. Jagadish, Synthesis and characterizations of aluminium 2024 and graphene metal matrix composites by powder metallurgy means, SSRG Int. J. Mech. Eng. 2 (7) (2015) 13-17.

[10] B.Q. Ochieze, C.C. Nwobi-Okoye, P.N. Atamuo, Experimental study of the effect of wear parameters on the wear behaviour of a356 alloy/cow horn particulate composites, Defense Technol. 1 (2018) 77-82.

[11] A.M. Cardinale, D. Macci, G. Luciano, E. Canepa, P. Traverso, Thermal and corrosion behaviour of as cast Al-Si alloys with rare earth elements, J. Alloys Compd. (2016) 1-10.

[12] A. Ramaswamy, A.V. Perumal, S. Jerold, S. Chelladurai, Investigation on mechanical properties and dry sliding wear characterization of stir cast LM13 aluminium alloy- $\mathrm{ZrB}_{2}-\mathrm{TiC}$ particulate hybrid composites, Mater. Res. Express (2019), https://doi.org/10.1088/2053-1591/ab0ef8.

[13] J. Fayomi, A.P.I. Popoola, O.M. Popoola, Corrosion performance and thermal behaviour of AA8011 reinforced with hybrid nano $\mathrm{ZrB}_{2}+\mathrm{Si}_{3} \mathrm{~N}_{4}$ Particulates for Automobile Applications, Mater. Res. Express 6 (11) (2019) 1150e2.

[14] V.K. Singh, S. Chauhan, P.C. Gope, A.K. Chaudhary, Enhancement of wettability of aluminum-based silicon carbide reinforced particulate metal matrix composite, High Temp. Mater. Process. (2014), https://doi.org/10.1515/htmp2014-0043.

[15] S.V. Prasad, R. Asthana, Aluminum metal-matrix composites for automotive applications: tribological considerations, Tribol. Lett. 17 (3) (2004) 445-453.

[16] J. Hirsch, Recent development in aluminium for automotive applications, Trans. Nonferrous Metals Soc. China 24 (2014) 1995-2002.

[17] A.A. Adebisi, M.A. Maleque, M.M. Rahman, Metal matrix composite brake rotor: historical development and product life cycle analysis, Int. J. Automot. Mech. Eng. 4 (2011) 471-480.

[18] P. Sharma, S. Sharma, D. Khanduja, Production and some properties of $\mathrm{Si}_{3} \mathrm{~N}_{4}$ reinforced aluminium alloy composites, J. Asian Ceram. Soc. 3 (2015) 352-359.

[19] B. Valdez, S. Kiyota, M. Stoytcheva, R. Zlatev, J.M. Bastidas, Cerium-based conversion coatings to improve the corrosion resistance of aluminium alloy 6061-T6, Corrosion Sci. 87 (2014) 141-149.

[20] K. Gajalakshmi, S. Kathiresa, K.S. Sreenivasan, S. Ravindran, Investigation of microstructure and mechanical properties of silicon nitride reinforced ammc using stir casting method, IOSR J. Mech. Civ. Eng. (2014) 61-65.

[21] J. Fayomi, A.P.I. Popoola, O.M. Popoola, O.P. Oladijo, Effect of silicon nitride $\left(\mathrm{Si}_{3} \mathrm{~N}_{4}\right)$ addition on the mechanical and tribological performance of Al-Fe-Si Alloy (AA8011), Mater. Sci. Forum 982 (2020) 34-38. In Proceedings of 2019 3rd International Conference on Materials Sciences and Nanomaterials (ICMSN 2019), Oxford, England, 22-24 July 2019.

[22] Astm E2007 2550, Standard test method for thermal stability by thermogravimetry (United States of America. https://www.astm.org/Standard/alphalists/E.html.

[23] C.F. John, R.C. Paul, S.C.E. Singh, J. Jacobjose, T. Ramkumar, G.S. Hikku, R.K. Sharma, P. Sengottuvel, Corrosion behavior of $\mathrm{ZrC}$ particles reinforcement with Al-12Si composites by weight loss method using acidic media, Bull. Pol. Acad. Sci. Tech. Sci. 66 (1) (2018), https://doi.org/10.24425/119053.

[24] P.V.K. Raju, K.A. Reddy, J.B. Rao, N.R.M.R. Bhargava, M.I. Reddy, Study of corrosion of Al-Cu hypoeutectic alloys and $\mathrm{Al}-\mathrm{Cu}$ composite fabricated using stir casting technique, Mater. Today (2018) 1776-1784. In Proceedings of PMME 2016.

[25] R. Venkatesh, V.S. Rao, Thermal, corrosion and wear analysis of copper-based metal matrix composites reinforced with alumina and graphite, Defence Technol. 14 (4) (2018) 346-355.

[26] R. Cao, J.X. Jiang, C. Wu, X.S. Jiang, Effect of addition of Si on thermal and electrical properties of Al-Si-Al $\mathrm{O}_{3}$ composites, IOP Conf. Ser. Mater. Sci. Eng. (2017), 012001, https://doi.org/10.1088/1757-899X/213/1/012001. In Proceedings of 2017 Global Conference on Polymer and Composite Materials (PCM 2017). 
[27] I.A. Zhukov, A.A. Kozulin, A.P. Khrustalyov, A.E. Matveev, V.V. Platov, A.B. Vorozhtsov, T.V. Zhukova, V.V. Promakhov, The impact of particle reinforcement with $\mathrm{Al}_{2} \mathrm{O}_{3}, \mathrm{TiB}_{2}$, and $\mathrm{TiC}$ and severe plastic deformation treatment on the combination of strength and electrical conductivity of pure aluminum,
Metals 9 (1) (2019) 65.

[28] S. Suresh, G. Harinath Gowd, M.L.S. Devakumar, Corrosion behavior of A

$7075 / \mathrm{Al}_{2} \mathrm{O}_{3} / \mathrm{SiC}$ MMNCs by weight loss method, J. Bio Tribo Corrosion 4 (2018) 62, https://doi.org/10.1007/s40735-018-0182-8. 